\section{(2)} OPEN ACCESS

\title{
Unmet need in rheumatology: reports from the Targeted Therapies meeting 2019
}

\author{
Kevin L Winthrop (1) ,' Michael E Weinblatt, ${ }^{2}$ Joan Bathon, ${ }^{3}$ Gerd R Burmester, ${ }^{4}$ \\ Philip J Mease (D) , ${ }^{5}$ Leslie Crofford, ${ }^{6}$ Vivian Bykerk, ${ }^{7}$ Maxime Dougados, ${ }^{8}$ \\ James Todd Rosenbaum, ${ }^{1,9}$ Xavier Mariette, ${ }^{10}$ Joachim Sieper, ${ }^{11}$ Fritz Melchers, $^{12}$ \\ Bruce N Cronstein, ${ }^{13}$ Ferry C Breedveld, ${ }^{14}$ Joachim Kalden, ${ }^{15}$ Josef S Smolen, ${ }^{16}$ \\ Daniel Furst ${ }^{5,17,18}$
}

For numbered affiliations see end of article.

\section{Correspondence to} Dr Kevin L Winthrop, Oregon Health Sciences University, Portland, OR 97239, USA; winthrop@ohsu.edu

Received 8 August 2019 Accepted 4 October 2019 Published Online First 29 October 2019

\section{Check for updates}

(C) Author(s) (or their employer(s)) 2020. Re-use permitted under CC BY-NC. No commercial re-use. See rights and permissions. Published by BMJ.

To cite: Winthrop $\mathrm{KL}$, Weinblatt ME, Bathon J, et al. Ann Rheum Dis 2020;79:88-93.

\section{ABSTRACT}

Objectives To detail the greatest areas of unmet scientific and clinical needs in rheumatology.

Methods The 21st annual international Advances in Targeted Therapies meeting brought together more than 100 leading basic scientists and clinical researchers in rheumatology, immunology, epidemiology, molecular biology and other specialties. During the meeting, breakout sessions were convened, consisting of 5 disease-specific groups with 20-30 experts assigned to each group based on expertise. Specific groups included: rheumatoid arthritis, psoriatic arthritis, axial spondyloarthritis, systemic lupus erythematosus and other systemic autoimmune rheumatic diseases. In each group, experts were asked to identify unmet clinical and translational research needs in general and then to prioritise and detail the most important specific needs within each disease area.

Results Overarching themes across all disease states included the need to innovate clinical trial design with emphasis on studying patients with refractory disease, the development of trials that take into account disease endotypes and patients with overlapping inflammatory diseases, the need to better understand the prevalence and incidence of inflammatory diseases in developing regions of the world and ultimately to develop therapies that can cure inflammatory autoimmune diseases.

Conclusions Unmet needs for new therapies and trial designs, particularly for those with treatment refractory disease, remain a top priority in rheumatology.

\section{BACKGROUND}

The Advances in Targeted Therapies meeting (ATT) has met annually for 21 years, bringing together clinical scientists and immunology and molecular biology experts from around the world. The meeting focuses on clinical and translational research, in immune-mediated inflammatory diseases (IMIDs) and stimulates collaboration between basic scientists and clinicians. The meeting's objective is to update participants regarding the latest insights regarding disease mechanism(s) and pathophysiology and recent developments with both existing and novel targeted therapies in the field of IMIDs with a focus on rheumatological diseases. Previously, a consensus document describing the recommended use of targeted therapies within rheumatology was produced from this meeting. ${ }^{1}$ However, with the expanse of targeted therapies and the recent clinical recommendations

\section{Key messages}

What is already known about this subject?

- Key unmet needs in field of rheumatology clinical and basic science research have been highlighted previously, but vary over time as the field progresses.

\section{What does this study add?}

- The Advances in Targeted Therapies meeting (ATT) focuses on clinical and translational research, in immune-mediated inflammatory diseases (IMIDs) and stimulates collaboration between basic scientists and clinicians. With the 2019 meeting, we reviewed, updated and prioritised the unmet research needs in the field

- This effort highlighted several overarching themes: the need to innovate clinical trial design with emphasis on studying patients with refractory disease, the development of trials that take into account disease endotypes and patients with overlapping inflammatory diseases, and the need to better understand the prevalence and incidence of inflammatory diseases in developing regions of the world.

\section{How might this impact on clinical practice?}

- The prioritisation and highlighting of research needs, particularly in aspects of clinical trial design, will ultimately result in improvements in therapy and potentially the better targeting of therapies toward patients with specific disease sub-types.

published from both American College of Rheumatology and the European Union League Against Rheumatism, ${ }^{2-4}$ a document covering all targeted therapies across all disease indications became too complex and voluminous as a single manuscript. Accordingly, the annual meeting's output was modified to discuss key unmet needs within the field, consistent with the meeting's underlying objective of promoting innovation and collaboration. ${ }^{5}$ With the 2019 meeting, we conducted a similar process to review and update these unmet needs, but in this case, prioritise and highlight the most important needs in the field. 


\section{METHODS}

We assigned conference participants to disease-specific breakout groups which included psoriatic arthritis (PsA), rheumatoid arthritis (RA), axial spondyloarthritis (axSpA), systemic lupus erythematous (SLE) and other systemic autoimmune rheumatic diseases including vasculitis. Experts in each group were tasked with identifying unmet needs in three categorical areas: clinical care, clinical science and therapeutic development and basic/ translational science. A 'facilitator' and 'rapporteur' led each group's discussion and summarised their results, and the groups were asked to highlight notable progress made towards previously identified needs as well as identify new areas of need. This year, each group was asked to then prioritise their discussion and detail the top several needs within each disease-specific area.

\section{RESULTS}

\section{Rheumatoid arthritis}

There was broad agreement that management of patients with RA who are refractory to available treatments ('refractory' or 'treatment resistant' RA) is arguably the greatest unmet need in RA (at least in the developed world). However, a careful clinical definition of the refractory state is needed, so that we are not confounding true treatment-refractory disease with patients with RA who are undertreated, non-adherent to treatment or who have comorbid fibromyalgia or other sources of non-inflammatory pain. Once a clinical definition of 'refractory' RA is achieved, a molecular definition of the refractory state should follow and should be differentiated from molecular definitions of early RA, established RA, RA in flare and RA in remission. Single cell analysis of synovial and/or circulating cells (including gene expression) may enable us to phenotype RA into subgroups or states of disease. ${ }^{6}$ Molecular characteristics at single cell level should be compared with whole synovial tissue molecular profiling with the aim of identifying peripheral blood surrogates of tissue pathology (liquid biopsy) and treatment response. The definitions of molecular subgroups could eventually lead to a personalised approach to treatment. For example, data generated may suggest that a combination or sequence of biologics may be efficacious in some individuals. Alternatively, molecular subgrouping may identify novel targets proximal in the disease process-that is, in the early adaptive immune response-that could be targeted for drug development and clinical trials.

Importantly, patients who have received multiple biologics/ small molecules should not be excluded from clinical trials since they have the greatest unmet need. Novel targeted therapies should be studied in refractory patients, as should novel combinations or sequences of existing therapies, similar to the way oncologists use checkpoint inhibitors. In particular, we should carefully move forward with combination therapy studies in refractory patients, with a commitment to resolving issues of cost, safety (eg, infection and malignancy) and the reluctance of manufacturers to combine each other's agents. Efforts to identify optimal dosing and levels of our currently available therapies, as a single treatment or in combination, are also essential to optimise treatment of refractory patients. Finally, it is important to recognise that despite many successful therapies for RA, less than half of patients with RA are in remission, $10 \%-15 \%$ are refractory, and there is still no cure for this disease. ${ }^{7-9}$ Continued commitment on the part of our funding agencies, pharmaceutical partners and scientific investigators is essential to advance research and discovery efforts to understanding the heterogeneity of RA pathogenesis and effective sustainable treatments.

\section{Psoriatic arthritis}

In the last few years, there have been an increasing number of medications with different mechanisms of action which have shown benefit in PsA in randomised clinical trials and have been approved by regulatory agencies, including an IL12-23 inhibitor (ustekinumab), two IL-17A inhibitors (secukinumab and ixekizumab), an oral PDE4 inhibitor (apremilast), an oral JAK inhibitor (tofacitinib) and abatacept. ${ }^{10} 11$ While very gratifying, the homogeneity imposed by clinical trial design may exclude important patient subgroups. For example, the great majority of patients have polyarticular involvement (entry criteria: $\geq 3-5$ inflamed joints) with few studies examining oligoarticular disease ( $<5$ inflamed joints); thus, the common oligoarticular PsA represents an unmet need in PsA trials. Although the varied clinical domains of PsA, (eg, enthesitis, dactylitis, spondylitis) can show response to treatment, only a subset of patients demonstrate these domains and thus the measured response may not achieve statistical significance if the subset is too small. Furthermore, a domain such as PsA spondylitis, with symptomatic inflammatory back pain in about $15 \%$ and asymptomatic sacroiliitis in about $30 \%$ of patients, ${ }^{12}$ is not measured by the standards of axSpA trials, including centrally read MRI. The best way to measure oligoarticular disease in trials remains an unmet need, and since the oligoarticular phenotype is a common presentation in clinical practice, we are not able to entirely accurately extrapolate results from trials to clinical practice. For treatment of the spondylitis component of PsA, we rely on data from axSpA trials, which also may not be accurately extrapolatable. Trials of the IL-12/23 inhibitor ustekinumab and the IL-23 inhibitor risankizumab have failed in ankylosing spondylitis. ${ }^{13}$ Even though these agents have demonstrated benefit and been approved for PsA, their ability to benefit the spinal component of PsA remains unproven and needs to be tested.

Phase IIIB or IV trials which specifically enrich the patient population for the domain or subtype in question are needed. Enrolment criteria could require oligoarticular disease or spondylitis or enthesitis for example, although measurement techniques for these disease aspects still need to be developed. Specific ultrasound or MRI (eg, axial clinical and imaging measures for a spondylitis-specific trial, entheseal-specific measures and imaging for an enthesitis trial) are needed. It is not clear how the results of these trials could be incorporated into regulatory labelling for the medication, but these would provide important clinical data helpful for clinical decision-making.

A second area of major unmet need in PsA is management of the therapy refractory patients who have 'tried everything'. Emergence of new approved therapies will partially address this need, as would rational 'combination' studies. Clinicians are more frequently trying unapproved combination approaches, for example combining a biological medication (TNFi, IL-17i and so on) with an oral agent such as a PDE4i or JAKi. Combination therapy trials are urgently needed, although the safety of such combination approaches is unknown, particularly with regard to infection, where a greater risk has been suggested in some combination trials for RA. ${ }^{14}$

A third major area of unmet need is better understanding of, and accounting for, the role of central sensitisation (CSS) (chronic widespread pain, fibromyalgia) in amplifying symptom severity. Recent studies have demonstrated that 15\%-40\% of patients with PsA and other rheumatic, chronic pain and inflammatory conditions may have concomitant CSS. When CSS is concomitantly present with PsA, disease activity measures which include patient-reported outcomes, (eg, pain, patient global) 
are nearly twice as severe when compared with a similar PsA cohort that lacks CSS. ${ }^{15-17}$ Patients with PsA with concomitant CSS are less likely or unable to achieve targets of treatment such as minimal disease activity, ${ }^{16-18}$ Højgaard et al demonstrated in this population lack of correlation between tender entheseal examination and evidence of objective evidence of inflammation by ultrasound. ${ }^{17} 18$ While patients with CSS are historically excluded from PsA trials, it is difficult to exclude all such patients. Several measures have been developed to ascertain the presence of CSS/fibromyalgia; ${ }^{17}$ however, there remains a need for more objective biomarkers which are more feasible to use in clinical and trial settings. In this respect it is noteworthy, that the treat-to-target recommendations for PsA explicitly state that 'The choice of the target and of the disease activity measure should take comorbidities, patient factors and drug-related risks into account' (recommendation \#8); ${ }^{19}$ this simply means that an index developed for measuring disease activity in PsA should not be used to score a comorbid condition, alternatives will then have to be used. Similarly, a prerequisite for application of classification criteria for RA is that a patient has no other diagnosis, such as SLE. ${ }^{20}$

\section{Ankylosing spondyloarthritis}

In 2018, the spondyloarthritis discussion group identified a variety of unmet needs which included: understanding the relationship of peripheral disease to axial disease; early recognition and diagnosis of disease; understanding the causes/relationship of extra-articular disease including bowel and eye disease to the joint disease; improved imaging technologies and interpretation; development of biomarkers for prognosis and choice of therapy; a wider choice of biological therapies; an ability to improve prognosis (disease modifying treatment); direct comparison among TNF inhibitors with regard to efficacy and safety; more frequent disease remission; improved referral to a rheumatologist and international collaboration. ${ }^{21}$

Although this list is comprehensive, additional themes were identified as most important. First, the need to better understand the microbiome is paramount. While it is highly likely that the gut microbiome is contributing to the disease, we do not know which bacteria are most important, which portion of the bowel is most important, the mechanism by which the bacteria affect the disease, the role of non-gut microbiota, the role of nonbacterial microbiota or how best to therapeutically alter the gut microbiome as by diet of faecal transplant. Second, the failure to establish IL-23 as an effective therapeutic target in ankylosing spondylitis means that we need to understand more completely the IL-23-IL-17 axis and the role of IL-23 and additional cytokines in the molecular pathogenesis of this disease. ${ }^{22-25}$ This effort should include a more complete understanding of the relative function of all members of the IL-17 family, including IL-17F and further understanding of which cells secrete IL-17 and why this does not seem to be under the control of IL-23 in this disease. ${ }^{26}$ We also need a better understanding as to how the disease results in both new bone formation and osteoporosis. ${ }^{27}$ Unfortunately, it still takes many years in daily clinical practice before a diagnosis of axial SpA is made. ${ }^{28} 29$ Therefore, approaches for referral in primary care and for early diagnosis have to be further developed and implemented. Last, there is still further need for international agreement (and implementation) on nomenclature of axial SpA. ${ }^{3031}$

\section{Systemic lupus erythematosus}

Recent failures of clinical trials in SLE demonstrate weaknesses in current methodology and opportunities for improvement in multiple areas. ${ }^{32-37}$ The theme of improving clinical trial design, including limiting disease heterogeneity, was prioritised in discussion. Specifically, learning from already available data was deemed essential. Analysis of the primary data from completed clinical trials, especially combining those from several studies, can provide essential insights that can guide decisions for new studies. ${ }^{38}$ Comparing the characteristics of the patients that participated in the trials with the data that are available from independent patient registries could be helpful to identify a bias in trial patient selection that might help to better understand trial outcomes. Issues that may confound clinical trials, including which patients should, or perhaps more importantly, should not be enrolled can be addressed using this type of analysis. Furthermore, evaluation of potential outcome measures ${ }^{39-41}$ and the effects of background therapy or comorbidities that impact relative response to the study drug can be determined. This type of analysis has limitations related to which patients were actually enrolled in the trials to be analysed. Here, an appropriate serological test to identify autoantibody positive patients based on sound technology is paramount. ${ }^{4243}$ Other datasets that may inform clinical trial design in different ways include patient registry studies, electronic medical record cohorts and administrative datasets, although issues of data quality, completeness and timeliness must be considered. ${ }^{44-47}$ Lupus trials are typically conducted with background therapy 32354849 and there is little agreement on how this should be controlled during the conduct and analysis of a study. ${ }^{43}$ In fact, the 'standard of care' medication in SLE in general has not been defined. ${ }^{4350}$

There are important ongoing issues surrounding the disease heterogeneity that also affect clinical trial design. ${ }^{43}$ With respect to inclusion criteria, targeting a single organ or specific subgroup could lead to more definitive conclusions regarding a study drug. ${ }^{51}$ The marked variability in disease severity of enrolled participants could also impact the ability to draw conclusions. ${ }^{52}$ For example, including participants with low disease activity could introduce floor effects that limit the ability to separate placebo from active treatment. On the other hand, patients with the greatest need of novel treatment approaches, namely with life threatening disease, ${ }^{53}$ are usually excluded from clinical trials. The impact of disease duration and previous treatment on the study population may also influence the effect of a study drug. The selected outcome measures can substantially influence whether a clinical trial meets its intended endpoint. New potential outcome measures have been proposed, such as the SLE-disease activity score ${ }^{54}$ intended as a continuous variable and the Lupus Low Disease Activity State. ${ }^{55}$ Another outcome measure, LuMOS, was developed from analysis of the belimumab trials and shows superior ability to detect change compared with the standard SRI-4. ${ }^{38}$ Other potentially novel outcome variables for this heterogeneous disease might include hierarchical outcomes. Using biomarkers either for inclusion or outcome may solve issues surrounding disease heterogeneity.

Novel trial designs that could be used for SLE include adaptive designs currently used in oncology. ${ }^{56}$ Drug withdrawal trials ${ }^{57}$ or trials that use flare for inclusion or outcome could also be considered as they allow the participation of patients with more severe disease. Novel designs might focus on reducing the impact of placebo response, including placebo response related to pretrial non-compliance. ${ }^{5859}$ In considering targets of treatment, it is tempting to focus on autoimmune inflammatory manifestations where exciting new discoveries provide novel targets. ${ }^{60}$ However, it is essential to include patient-focused unmet needs. ${ }^{6162}$ These include symptoms that impact quality of 
life such as pain, fatigue and cognitive dysfunction ('lupus fog') which are typically resistant to immune-focused therapies. Treatments that could improve medication adherence, especially in socially deprived populations and by approaches which require less frequent dosing, or that can mitigate the important concern of reproductive issues, are needed. Overall, there are abundant opportunities for clinical scientists, pharmaceutical companies and regulatory bodies to collaborate towards improved methodology to provide better patient outcomes.

\section{Other systemic autoimmune rheumatic diseases}

This group highlighted the unmet needs primarily within systemic sclerosis this year, and similar to other groups, identified the issue of improving clinical trials of utmost importance. Recent and current clinical trials have failed to demonstrate efficacy for a variety of agents in the treatment of this disease, although the results suggest that some disease manifestations may actually be improved by certain agents. ${ }^{63}$ One difficulty in designing clinical trials to date has been the heterogeneity of disease manifestations. It might be appropriate to design trials for a specific manifestation for example (eg, lung disease). Alternatively an acceptable, sensitive, specific and quantitative combined outcome measure that would be acceptable to regulatory agencies could speed the design and development of trials for registration of new therapeutic agents. ${ }^{64} \mathrm{~A}$ dearth of predictive biomarkers also makes it difficult to target drug trials to those with the greatest potential for benefit from specific therapeutic interventions. ${ }^{656}$ Finally, inclusion of patient-reported outcomes of specific manifestations (eg, calcinosis) could allay patients' concerns about entering trials. ${ }^{67}$

Table 1 Identified unmet research needs of high priority within RA PSA, AxSpa, SLE and other systemic autoimmune rheumatic diseases

\begin{tabular}{|c|c|}
\hline \multirow[t]{2}{*}{ Rheumatoid arthritis } & $\begin{array}{l}\text { The need to better define treatment 'refractory' states both } \\
\text { phenotypically and molecularly }\end{array}$ \\
\hline & $\begin{array}{l}\text { The need to focus on refractory patients in both the study } \\
\text { of novel targeted therapies and in the study of existing } \\
\text { therapies in novel combinations or sequences }\end{array}$ \\
\hline \multirow[t]{2}{*}{ Psoriatic arthritis } & $\begin{array}{l}\text { Understanding differential therapeutic effects on different } \\
\text { clinical domains in PsA such as enthesitis }\end{array}$ \\
\hline & $\begin{array}{l}\text { Further evaluation of combination therapies and strategic } \\
\text { trials including the use of sequential therapies, controlled } \\
\text { withdrawal, the treatment of early disease and the } \\
\text { treatment of monoarticular or oligoarticular disease }\end{array}$ \\
\hline \multirow[t]{2}{*}{$\begin{array}{l}\text { Ankylosing } \\
\text { spondyloarthritis }\end{array}$} & $\begin{array}{l}\text { Understanding the role of the microbiome in disease } \\
\text { pathogenesis and potential therapy }\end{array}$ \\
\hline & $\begin{array}{l}\text { Understanding disease pathology specifically with regard to } \\
\text { why II-23 inhibition does not improve the disease. }\end{array}$ \\
\hline \multirow[t]{2}{*}{$\begin{array}{l}\text { Systemic lupus } \\
\text { erythematosus }\end{array}$} & $\begin{array}{l}\text { Improving clinical trial design by reducing heterogeneity } \\
\text { of participants, developing new outcome disease activity } \\
\text { measures, standardising serological testing and conducting } \\
\text { organ-specific trials }\end{array}$ \\
\hline & $\begin{array}{l}\text { Consider alternative trial designs including adaptive trials } \\
\text { and withdrawal trials }\end{array}$ \\
\hline \multirow[t]{2}{*}{$\begin{array}{l}\text { Other systemic } \\
\text { autoimmune rheumatic } \\
\text { diseases }\end{array}$} & $\begin{array}{l}\text { Improving clinical trial design, specifically with reducing } \\
\text { heterogeneity in disease endotypes and the use of organ- } \\
\text { specific outcome measures }\end{array}$ \\
\hline & $\begin{array}{l}\text { Identification of predictive biomarkers and the inclusion of } \\
\text { patient-reported outcomes of specific manifestations (eg, } \\
\text { calcinosis) for clinical trials }\end{array}$ \\
\hline
\end{tabular}

axSpA, axial spondyloarthritis; PsA, psoriatic arthritis; RA, rheumatoid arthritis; SLE, systemic lupus erythematous.

\section{SUMMARY}

The convening of the 21st ATT afforded the possibility to discuss and articulate major unmet needs in the field of rheumatology, and across domains there were several overarching perceived unmet needs (table 1). It was generally understood that there has not been sufficient emphasis on trial designs which concentrated on well-defined disease subtypes. Many diseases have multiple subtypes (eg, axial and peripheral PsA or limited/diffuse systemic sclerosis with multiple serological subtypes) and trial designs which mix those subtypes could obscure the success of treatments in specific subgroups. Likewise, trial designs which are able to dissect (or include) overlapping diseases are also needed.

While there has been some success in treating moderate to severe patients with various inflammatory rheumatic diseases and even inclusion of some patients with Disease Modifying anti-Rheumatic Drugs (DMARD)-refractory disease in RA, this remains a top unmet need in RA that has been even less carefully examined in patients with other diseases. For example, patients with PsA are often included in trials only if they have been naïve to previous conventional synthetic DMARD (csDMARDs) or biologic DMARD (bDMARDs); more attention needs to be paid to patients who are more 'difficult-to-treat' across all conditions, as well as those who have multiple complications or comorbidities or those who have failed other csDMARDs or bDMARDs.

Last, while progress has been made in treating patients who used to have unmet need within countries and regions such as Australia, Japan, North America and the European Union, it was highlighted that more emphasis needed to be placed on understanding unmet needs in other countries and continents such as Africa, multiple areas in Asia and Central and South America.

\section{Author affiliations}

${ }^{1}$ Oregon Health Sciences University, Portland, Oregon, USA

${ }^{2}$ Brigham and Womens Hospital, Boston, Massachusetts, USA

${ }^{3}$ Columbia University, College of Physicians \& Surgeons, New York City, New York, USA

${ }^{4}$ Charité University Hospital, Berlin, Germany

${ }^{5}$ Swedish Medical Center, University of Washington, Seattle, Washington, USA

${ }^{6}$ Vanderbilt University, Nashville, Tennessee, USA

${ }^{7}$ Hospital for Special Surgery, New York City, New York, USA

${ }^{8}$ Hôpital Cochin, Paris, France

${ }^{9}$ Legacy Devers Eye Institute, Portland, Oregon, USA

${ }^{10}$ Paris-Sud University, APHP Université Paris-Saclay, Hôpital Bicêtre, Le Kremlin Bicêtre, France

${ }^{11}$ Department of Gastroenterology, Infectious Diseases and Rheumatology, Campus Benjamin Franklin, Charité, Berlin, Germany

${ }^{12}$ Max Planck Institute for Infection Biology, Berlin, Germany

${ }^{13}$ NYU School of Medicine, New York City, New York, USA

${ }^{14}$ Leiden University Medical Center, Leiden, The Netherlands

${ }^{15}$ University of Erlangen, Erlangen, Germany

${ }^{16}$ Division of Rheumatology, Department of Medicine 3, Medical University of, Vienna, Vienna, Austria

${ }^{17}$ University of California, Los Angeles Medical Center, Los Angeles, CA, USA

${ }^{18}$ University of Florence, Florence, Italy

Contributors All coauthors contributed to this manuscript's creation in all aspects including data gathering, analysis, writing and critical revision of the manuscript.

Funding The authors have not declared a specific grant for this research from any funding agency in the public, commercial or not-for-profit sectors.

Competing interests KLW reports personal fees from Pfizer, grants and personal fees from BMS, personal fees from AbbVie, personal fees from UCB, personal fees from Lilly, personal fees from Galapagos, personal fees from GSK, personal fees from Roche outside the submitted work. JB reports personal fees from AbbVie outside the submitted work. MD reports grants and personal fees from Pfizer, grants and personal fees from Abbvie, grants and personal fees from Lilly, grants and personal fees from Novartis, grants and personal fees from UCB, grants and personal fees from Merck, grants and personal fees from Roche, during the conduct of the study. JTR reports grants from Pfizer, personal fees from Abbvie, personal fees from Gilead, personal fees from Santen, personal fees from Roche, personal fees from 
Novartis, personal fees from UCB, personal fees from Corvus, personal fees from Horizon, personal fees from Celldex, personal fees from Eyevensys, personal fees from UpToDate, personal fees from Janssen outside the submitted work. XM reports personal fees from BMS, personal fees from GILEAD, personal fees from PFIZER, personal fees from SAMSUNG, personal fees from UCB outside the submitted work. BNC has multiple patents, none of which are relevant. In addition he has multiple grants from NIH. JSS reports grants and personal fees from AbbVie, personal fees from Amgen, personal fees from AstraZeneca, personal fees from Astro, personal fees from Bristol-Myers Squibb, personal fees from Celgene, personal fees from Celltrion, personal fees from ILTOO, grants and personal fees from Janssen, grants and personal fees from Lilly, personal fees from MSD, grants and personal fees from Novartis-Sandoz, personal fees from Novo-Nordisk, grants and personal fees from Roche, personal fees from Samsung Bioepis, personal fees from Sanofi, personal fees from UCB, grants and personal fees from Pfizer outside the submitted work. DF reports grant/research support from Actelion, grant/research support from Amgen, grant/research support from BMS, grant/research support from Corbus, grant/ research support from Galapagos GSK, grant/research support from NIH, grant/ research support from Novartis, grant/research support from Pfizer, grant/research support from Sanofi, grant/research support from Roche/Genentech, personal fees from Actelion, personal fees from Amgen, personal fees from BMS, personal fees from Corbus, personal fees from Galapagos, personal fees from Novartis, personal fees from Pfizer outside the submitted work.

Patient consent for publication Not required.

Provenance and peer review Not commissioned; externally peer reviewed.

Data availability statement All data relevant to the study are included in the article or uploaded as supplementary information.

Open access This is an open access article distributed in accordance with the Creative Commons Attribution Non Commercial (CC BY-NC 4.0) license, which permits others to distribute, remix, adapt, build upon this work non-commercially, and license their derivative works on different terms, provided the original work is properly cited, appropriate credit is given, any changes made indicated, and the use is non-commercial. See: http://creativecommons.org/licenses/by-nc/4.0/.

ORCID iDs

Kevin L Winthrop http://orcid.org/0000-0002-3892-6947

Philip J Mease http://orcid.org/0000-0002-6620-0457

\section{REFERENCES}

1. Furst DE, Keystone EC, So AK, et al. Updated consensus statement on biological agents for the treatment of rheumatic diseases, 2012. Ann Rheum Dis 2013;72:ii2-34

2. Singh JA, Saag KG, Bridges SL, et al. 2015 American College of rheumatology guideline for the treatment of rheumatoid arthritis. Arthritis Rheumatol 2016;68:1-26.

3. Smolen JS, Landewé R, Bijlsma J, et al. EULAR recommendations for the management of rheumatoid arthritis with synthetic and biological disease-modifying antirheumatic drugs: 2016 update. Ann Rheum Dis 2017;76:960-77.

4. Gossec L, Smolen JS, Ramiro S, et al. European League against rheumatism (EULAR) recommendations for the management of psoriatic arthritis with pharmacological therapies: 2015 update. Ann Rheum Dis 2016:75:499-510.

5. Winthrop KL, Strand V, van der Heijde DM, et al. The unmet need in rheumatology: reports from the targeted therapies meeting 2016. Clin Exp Rheumatol 2016;34:69-76

6. Zhang F, Wei K, Slowikowski K, et al. Defining inflammatory cell states in rheumatoid arthritis joint synovial tissues by integrating single-cell transcriptomics and mass cytometry. Nat Immunol 2019;20:928-42.

7. Emery P, Breedveld FC, Hall S, et al. Comparison of methotrexate monotherapy with a combination of methotrexate and etanercept in active, early, moderate to severe rheumatoid arthritis (comet): a randomised, double-blind, parallel treatment trial. The Lancet 2008;372:375-82.

8. Becede M, Alasti F, Gessl I, et al. Risk profiling for a refractory course of rheumatoid arthritis. Semin Arthritis Rheum 2019.

9. Heijde D, Strand V, Tanaka Y, et al. Tofacitinib in combination with methotrexate in patients with rheumatoid arthritis: clinical efficacy, radiographic, and safety outcomes from a twenty-four-month, phase III study. Arthritis Rheumatol 2019;71:878-91.

10. Mease PJ. Current and emerging treatments for psoriatic arthritis. In: Yamauchi PS, ed. Biologic and systemic agents in dermatology. Cham: Springer International Publishing, 2018: 175-85.

11. Mease PJ. Biologic therapy for psoriatic arthritis. Rheum Dis Clin North Am 2015:41:723-38.

12. Baraliakos $X$, Coates $L C$, Braun J. The involvement of the spine in psoriatic arthritis. Clin Exp Rheumatol 2015;33:S31-5.

13. Mease P. Ustekinumab fails to show efficacy in a phase III axial spondyloarthritis program: the importance of negative results. Arthritis Rheumatol 2019;71:179-81.
14. Weinblatt M, Schiff M, Goldman A, et al. Selective costimulation modulation using abatacept in patients with active rheumatoid arthritis while receiving etanercept: a randomised clinical trial. Ann Rheum Dis 2007;66:228-34.

15. Brikman $S$, Furer $V$, Wollman J, et al. The effect of the presence of fibromyalgia on common clinical disease activity indices in patients with psoriatic arthritis: a crosssectional study. J Rheumatol 2016;43:1749-54.

16. Højgaard P, Ellegaard K, Nielsen SM, et al. Pain mechanisms and ultrasonic inflammatory activity as prognostic factors in patients with psoriatic arthritis: a prospective cohort study. Arthritis Care Res 2019;71:798-810.

17. Fibromyalgia MPJ. A missed comorbidity in spondyloarthritis: prevalence and impact on assessment and treatment. Curr Opin Rheumatol 2017;29:304-10.

18. Moltó A, Etcheto A, Gossec L, et al. Evaluation of the impact of concomitant fibromyalgia on TNF alpha blockers' effectiveness in axial spondyloarthritis: results of a prospective, multicentre study. Ann Rheum Dis 2018;77:533-40.

19. Smolen JS, Schöls M, Braun J, et al. Treating axial spondyloarthritis and peripheral spondyloarthritis, especially psoriatic arthritis, to target: 2017 update of recommendations by an international Task force. Ann Rheum Dis 2018;77:3-17.

20. Aletaha D, Neogi T, Silman AJ, et al. 2010 rheumatoid arthritis classification criteria: an American College of Rheumatology/European League against rheumatism collaborative initiative. Arthritis Rheum 2010;62:2569-81.

21. Winthrop KL, Weinblatt ME, Crow MK, et al. Unmet need in rheumatology: reports from the targeted therapies meeting 2018. Ann Rheum Dis 2019;78:872-8.

22. Rosenbaum JT, Asquith M. The microbiome and HLA-B27-associated acute anterior uveitis. Nat Rev Rheumatol 2018:14:704-13.

23. Choi RY, Asquith M, Rosenbaum JT. Fecal transplants in spondyloarthritis and uveitis: ready for a clinical trial? Curr Opin Rheumatol 2018;30:303-9.

24. Baeten D, Østergaard M, Wei JC-C, et al. Risankizumab, an IL-23 inhibitor, for ankylosing spondylitis: results of a randomised, double-blind, placebo-controlled, proof-of-concept, dose-finding phase 2 study. Ann Rheum Dis 2018;77:1295-302.

25. Siebert S, Millar NL, McInnes IB. Why did IL-23p19 inhibition fail in as: a tale of tissues, trials or translation? Ann Rheum Dis 2019;78:1015-8.

26. Ciccia F, Guggino G, Rizzo A, et al. Type 3 innate lymphoid cells producing $\mathrm{IL}-17$ and IL-22 are expanded in the gut, in the peripheral blood, synovia fluid and bone marrow of patients with ankylosing spondylitis. Ann Rheum Dis 2015; 74:1739-47

27. Gravallese EM, Schett G. Effects of the IL-23-IL-17 pathway on bone in spondyloarthritis. Nat Rev Rheumatol 2018;14:631-40.

28. Seo MR, Baek HL, Yoon HH, et al. Delayed diagnosis is linked to worse outcomes and unfavourable treatment responses in patients with axial spondyloarthritis. Clin Rheumatol 2015;34:1397-405.

29. Rosenbaum JT, Pisenti L, Park Y, et al. Insight into the quality of life of patients with ankylosing spondylitis: real-world data from a US-based life impact survey. Rheumatol Ther 2019;6:353-67.

30. Braun J. Axial spondyloarthritis: thoughts about Nomenclature and treatment targets. Clin Exp Rheumatol 2012;30:S132-5.

31. Erbil J, Espinoza LR. Nonradiographic axial spondyloarthritis background and confounding factors of this new terminology: an appraisal. Clin Rheumatol 2015:34:407-11.

32. Clowse MEB, Wallace DJ, Furie RA, et al. Efficacy and safety of Epratuzumab in moderately to severely active systemic lupus erythematosus: results from two phase III randomized, double-blind, placebo-controlled trials. Arthritis Rheumatol 2017:69:362-75

33. Merrill JT, van Vollenhoven RF, Buyon JP, et al. Efficacy and safety of subcutaneous tabalumab, a monoclonal antibody to B-cell activating factor, in patients with systemic lupus erythematosus: results from ILLUMINATE-2, a 52-week, phase III, multicentre, randomised, double-blind, placebo-controlled study. Ann Rheum Dis 2016:75:332-40.

34. Kalunian KC, Merrill JT, Maciuca R, et al. A phase II study of the efficacy and safety of rontalizumab (rhuMAb interferon- $\alpha$ ) in patients with systemic lupus erythematosus (rose). Ann Rheum Dis 2016;75:196-202.

35. Merrill JT, Shanahan WR, Scheinberg M, et al. Phase III trial results with blisibimod, a selective inhibitor of B-cell activating factor, in subjects with systemic lupus erythematosus (SLE): results from a randomised, double-blind, placebo-controlled trial. Ann Rheum Dis 2018;77:883-9.

36. Hruskova Z, Tesar V. Lessons learned from the failure of several recent trials with biologic treatment in systemic lupus erythematosus. Expert Opin Biol Ther 2018; 18:989-96

37. Mahieu MA, Strand V, Simon LS, et al. A critical review of clinical trials in systemic lupus erythematosus. Lupus 2016;25:1122-40.

38. Abrahamowicz M, Esdaile JM, Ramsey-Goldman R, et al. Development and validation of a novel evidence-based lupus multivariable outcome score for clinical trials. Arthritis Rheumatol 2018:70:1450-8.

39. Tarazi M, Gaffney RG, Feng R, et al. Evaluating cutaneous lupus disease activity end points and their effects on quality of life as an outcome measure for clinical trials. $\mathrm{Br} \mathrm{J}$ Dermatol 2019:181:841-2.

40. Oon S, Huq M, Golder V, et al. Lupus low disease activity state (LLDAS) discriminates responders in the BLISS-52 and BLISS-76 phase III trials of belimumab in systemic lupus erythematosus. Ann Rheum Dis 2019;78:629-33. 
41. Morand EF, Trasieva T, Berglind A, et al. Lupus Low Disease Activity State (LLDAS) attainment discriminates responders in a systemic lupus erythematosus trial: post-hoc analysis of the Phase Ilb MUSE trial of anifrolumab. Ann Rheum Dis 2018;77:706-13.

42. Pisetsky DS, Spencer DM, Lipsky PE, et al. Assay variation in the detection of antinuclear antibodies in the sera of patients with established SLE. Ann Rheum Dis 2018;77:911-3.

43. Dall'Era M, Bruce IN, Gordon C, et al. Current challenges in the development of new treatments for lupus. Ann Rheum Dis 2019;78:729-35.

44. Tonner C, Schmajuk G, Yazdany J. A new era of quality measurement in rheumatology: electronic clinical quality measures and national registries. Curr Opin Rheumatol 2017;29:131-7.

45. Yazdany J, Robbins M, Schmajuk G, et al. Development of the American College of rheumatology's rheumatoid arthritis electronic clinical quality measures. Arthritis Care Res 2016:68:1579-90.

46. Narváez J, Borrell H, Sánchez-Alonso F, et al. Primary respiratory disease in patients with systemic lupus erythematosus: data from the Spanish rheumatology Society lupus registry (RELESSER) cohort. Arthritis Res Ther 2018;20.

47. Kearsley-Fleet L, Zavada J, Hetland ML, et al. The EULAR Study Group for registers and observational drug studies: comparability of the patient case mix in the European biologic disease modifying anti-rheumatic drug registers. Rheumatology 2015;54:1074-9.

48. Stohl W, Schwarting A, Okada M, et al. Efficacy and safety of subcutaneous belimumab in systemic lupus erythematosus: a Fifty-Two-Week randomized, doubleblind, placebo-controlled study. Arthritis Rheumatol 2017;69:1016-27.

49. Furie R, Khamashta M, Merrill JT, et al. Anifrolumab, an anti-interferon- $\alpha$ receptor monoclonal antibody, in moderate-to-severe systemic lupus erythematosus. Arthritis Rheumatol 2017;69:376-86.

50. Fanouriakis A, Kostopoulou M, Alunno A, et al. 2019 update of the EULAR recommendations for the management of systemic lupus erythematosus. Ann Rheum Dis 2019;78:736-45.

51. Aringer M, Strand V. Endpoints for randomised controlled trials in systemic lupus erythematosus. Clin Exp Rheumatol 2012;30:147-51.

52. Thanou A, Merrill JT. New trials in lupus and where are we going. Curr Rheumatol Rep 2018;20:34.

53. Aringer M, Burkhardt $H$, Burmester GR, et al. Current state of evidence on 'offlabel' therapeutic options for systemic lupus erythematosus, including biological immunosuppressive agents, in Germany, Austria and Switzerland - a consensus report. Lupus 2012;21:386-401.
54. Jesus D, Matos A, Henriques C, et al. Derivation and validation of the SLE disease activity score (SLE-DAS): a new SLE continuous measure with high sensitivity for changes in disease activity. Ann Rheum Dis 2019;78:365-71.

55. Franklyn K, Lau CS, Navarra SV, et al. Definition and initial validation of a lupus low disease activity state (LLDAS). Ann Rheum Dis 2016;75:1615-21.

56. Pickles T, Alten R, Boers M, et al. Adaptive trial designs in rheumatology: report from the OMERACT special interest group. J Rheumatol 2019;46:1406-8.

57. Canadian Hydroxychloroquine Study Group. A randomized study of the effect of withdrawing hydroxychloroquine sulfate in systemic lupus erythematosus. N Engl J Med 1991;324:150-4.

58. Oliveira-Santos M, Verani JFdeS, Camacho LAB, et al. Effectiveness of pharmaceutical care for drug treatment adherence in patients with systemic lupus erythematosus in Rio de Janeiro, Brazil: study protocol for a randomized controlled trial. Trials 2016;17:181.

59. Costedoat-Chalumeau N, Pouchot J, Guettrot-Imbert G, et al. Adherence to treatment in systemic lupus erythematosus patients. Best Pract Res Clin Rheumatol 2013;27:329-40.

60. Felten R, Dervovic E, Chasset F, et al. The 2018 pipeline of targeted therapies under clinical development for systemic lupus erythematosus: a systematic review of trials. Autoimmun Rev 2018;17:781-90.

61. Leuchten N, Bauernfeind B, Kuttner J, et al. Relevant concepts of functioning for patients with systemic lupus erythematosus identified in a Delphi exercise of experts and a literature review. Arthritis Care Res 2014;66:1895-904.

62. van Vollenhoven RF, Mosca M, Bertsias G, et al. Treat-to-target in systemic lupus erythematosus: recommendations from an international Task force. Ann Rheum Dis 2014;73:958-67.

63. Khanna D, Denton CP, Jahreis A, et al. Safety and efficacy of subcutaneous tocilizumab in adults with systemic sclerosis (faSScinate): a phase 2, randomised, controlled trial. The Lancet 2016;387:2630-40.

64. Khanna D, Berrocal VJ, Giannini EH, et al. The American College of rheumatology provisional composite response index for clinical trials in early diffuse cutaneous systemic sclerosis. Arthritis \& Rheumatology 2016;68:299-311.

65. Assassi S, Radstake TRDJ, Mayes MD, et al. Genetics of scleroderma: implications for personalized medicine? BMC Med 2013;11:9.

66. Stifano G, Sornasse T, Rice LM, et al. Skin gene expression is prognostic for the trajectory of skin disease in patients with diffuse cutaneous systemic sclerosis. Arthritis Rheumatol 2018:70:912-9.

67. Pellar RE, Tingey TM, Pope JE. Patient-reported outcome measures in systemic sclerosis (scleroderma). Rheum Dis Clin North Am 2016:42:301-16. 